\title{
Excitation of Rat Locus Coeruleus Neurons by Adenosine 5'-Triphosphate: Ionic Mechanism and Receptor Characterization
}

\author{
K.-Z. Shen and R. A. North \\ Vollum Institute, Oregon Health Sciences University, Portland, Oregon 97201
}

\begin{abstract}
ATP and several congeners were applied to locus coeruleus neurons in slices cut from rat pons. Whole-cell recording of membrane current showed that ATP caused an inward current at $-60 \mathrm{mV}$. Effective concentrations (applied by superfusion) were 3-300 $\mu \mathrm{M}$, and the peak current was about $150 \mathrm{pA}$ at $-60 \mathrm{mV}$. 2-Methylthioadenosine 5 '-triphosphate was slightly more potent than ATP, adenosine 5'-diphosphate was about equipotent with ATP, $\alpha, \beta$-methylene adenosine 5 '-triphosphate was slightly less potent than ATP, and $\beta, \gamma^{\prime}$-methylene adenosine $5^{\prime}$-triphosphate and adenosine $5^{\prime}$ monophosphate had little or no effect. Adenosine (100 $\mu \mathrm{M})$ caused small outward currents (40 pA). By changing the ionic composition of the pipette and extracellular solution, it was shown that the inward current resulted from both an increase in conductance to sodium ions and a reduction in conductance to potassium ions. It is concluded that rat locus coeruleus neurons express $P_{2}$ purinoceptors, activation of which depolarizes the cells predominately by increasing a conductance that allows sodium ions to enter the cell.
\end{abstract}

[Key words: ATP, locus coeruleus, $P_{2}$ receptor, sodium conductance, potassium conductance, purinoceptor]

Substantial evidence suggests that peripheral noradrenergic neurones can use ATP as a cotransmitter (Burnstock, 1986). Like the noradrenaline, the released ATP can act both at postjunctional receptors and at prejunctional receptors. The postjunctional effect is typically excitatory, involving membrane depolarization (see Silinsky, 1989), whereas the prejunctional effect results in inhibition of the further release of noradrenaline and ATP (e.g., Shinozuka et al., 1988; Kuelgen et al., 1989). Several types of receptor for ATP can be distinguished pharmacologically, and the most fully characterized distinction is between $P_{2 X}$ and $P_{2 \gamma}$ receptors. These can be separated according to the rank order of potency of agonists: for example, $\alpha, \beta$-methylene ATP $(\alpha, \beta$-Me-ATP) is more effective than 2-methylthio-ATP (2-MeS-ATP) at $P_{2 x}$ receptors, whereas the reverse order pertains for $P_{2 Y}$ receptors (Silinsky, 1989; Kennedy, 1990). The $P_{2 x}$ classification includes a receptor that seems to be a ligand-gated ion channel, whereas the $P_{2 Y}$ receptor is most commonly coupled to an increase in phosphatidyl inositol metabolism (see Silinsky, 1989).

It is not known whether ATP is a cotransmitter with noradrenaline in central noradrenergic neurons. Specifically, there is no information regarding presynaptic actions of ATP on the

\footnotetext{
Received June 15, 1992; revised Aug. 25, 1992; accepted Aug. 31, 1992.

This work was supported by NIH Grants DA03160, DA03161, and MH40416.

Correspondence should be addressed to Dr. R. A. North at the above address.

Copyright (C) 1993 Society for Neuroscience $0270-6474 / 93 / 130894-06 \$ 05.00 / 0$
}

release of noradrenaline (although adenosine is effective; Jackisch et al., 1985). Noradrenaline is released not only from the varicose terminals of the noradrenergic cells as they ramify in their several targets, but also from the soma-dendritic region (Egan et al., 1983). Here it acts at $\alpha_{2}$-adrenoceptors to hyperpolarize the cell and inhibit firing; its effect is detected electrophysiologically as an IPSP (Egan et al., 1983). This raises the possibility that co-released ATP may also act at the somadendritic membrane. One purpose of the present experiments was to seek such an action and to determine the receptor type(s) involved. There is also very little information regarding the direct postsynaptic actions of ATP on central neurons, in contrast to the several studies on peripheral tissues (Nicoll et al., 1990). Therefore, a second purpose of the experiments was to determine whether direct postsynaptic actions of ATP on central neurons might also result from activation of $P_{2 Y}$ receptors.

\section{Materials and Methods}

Rats (Sprague-Dawley, 150-200 gm) were killed under deep halothane anesthesia by severing the major blood vessels within the chest. A horizontal slice $(300 \mu \mathrm{m})$ containing the locus coeruleus was prepared as previously described (Williams et al., 1984). The slices were superfused in a flowing $(1.5 \mathrm{ml} / \mathrm{min})$ saline solution at $37^{\circ} \mathrm{C}$. The solution contained (in $\mathrm{mM}$ ) $\mathrm{NaCl}, 126 ; \mathrm{KCl}, 6.5 ; \mathrm{CaCl}_{2}, 2.4 ; \mathrm{MgCl}_{2}, 1.2 ; \mathrm{NaH}_{2} \mathrm{PO}_{4}, 1.2$; $\mathrm{NaHCO}_{3}, 19$; and glucose, 11; equilibrated with $95 \% \mathrm{O}_{2}$ and $5 \% \mathrm{CO}_{2}$. Unless stated, TTX $(1 \mu \mathrm{M})$ was added to the solution. Low-chloride solutions were made with sodium isethionate substitution, and lowsodium solutions, with Tris hydrochloride substitution.

Whole-cell recordings were made with pipettes of 2-5 M , having first made a high-resistance seal onto the cell surface. The pipette solution contained (in $\mathrm{mM}$ ) potassium gluconate, $125 ; \mathrm{NaCl}, 15 ; \mathrm{MgCl}_{2}$, 2; EGTA, 11; HEPES, 10; ATP, 1.5; and GTP, 0.2 (the $\mathrm{pH}$ was adjusted to 7.2 with about $5 \mathrm{~mm} \mathrm{KOH}$ ). When potassium-free solutions were used, cesium gluconate was substituted for potassium gluconate and $\mathrm{CsOH}$ was used to adjust the $\mathrm{pH}$. An Axopatch-1 B amplifier was used to measure membrane currents. The currents evoked by ATP were always less than $1 \mathrm{nA}$; thus, errors in potential measurement from the series pipette resistance would not exceed $5 \mathrm{mV}$. These were partially corrected using the amplifier control. Potentials reported have been corrected for the junction potential between the pipette solution (potassium gluconate) and the bath solution prior to making a gigaseal (usually pipette $10 \mathrm{mV}$ negative to bath).

Drugs used were adenosine $5^{\prime}$-triphosphate (ATP), adenosine 5 -diphosphate (ADP), $\alpha, \beta$-methylene adenosine $5^{\prime}$-triphosphate $(\alpha, \beta$-MeATP), $\beta, \gamma^{\prime}$-methylene adenosine 5 -triphosphate $\left(\beta, \gamma^{\prime}\right.$-Me-ATP), 2-methylthioadenosine $5^{\prime}$-triphosphate (2-MeS-ATP), adenosine $5^{\prime}$ monophosphate, and adenosine. They were purchased from Sigma.

Results are expressed as mean \pm SEM.

\section{Results}

Action of ATP at $-60 \mathrm{mV}$

ATP caused an inward current in all cells tested $(n=241)$. The current reached its peak value within $2-3 \mathrm{sec}$. With lower concentrations $(1-3 \mu \mathrm{M})$ the current remained at this level through- 
A

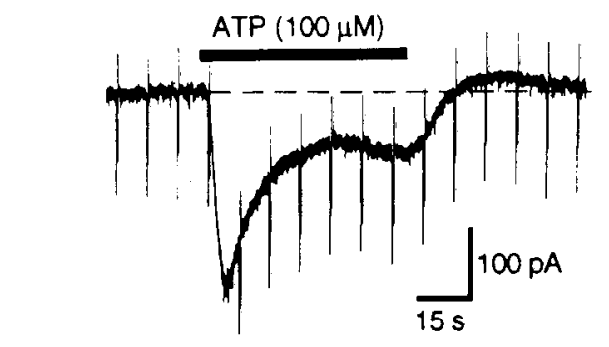

C

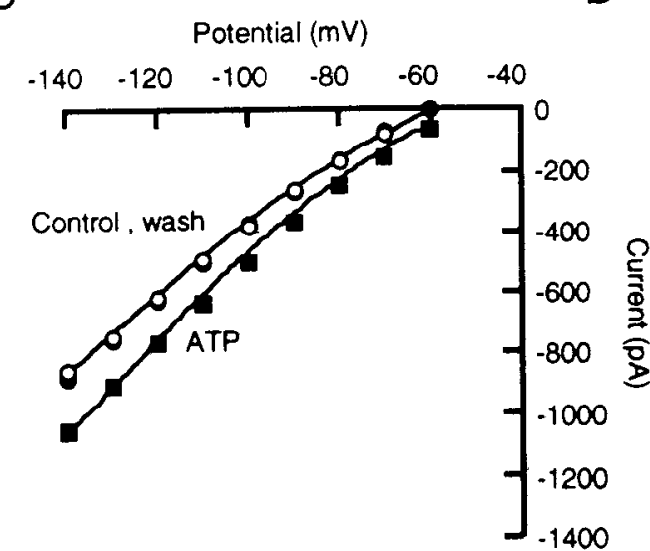

B

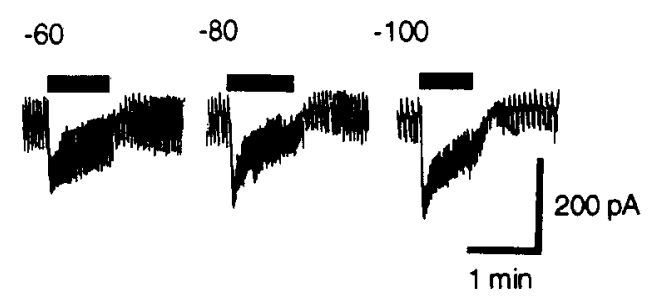

Figure 1. ATP evokes inward current. $A$, Current evoked by ATP desensitizes during the application. Holding potential, $-60 \mathrm{mV}$. In this and following figures, th te bar above the trace indicates the period during which the solution contained ATP. Downward deflections are currents in response to step hyperpolarization (voltage commands were $10 \mathrm{mV} / 500 \mathrm{msec}$, repeated at $0.2 \mathrm{~Hz}$ ). $B$, Responses to ATP $(100 \mu \mathrm{M})$ at three holding potentials (indicated above each trace). $C$, Current-voltage plots before, during and after washing out ATP $(300$ $\mu \mathrm{M})$. The $I / V$ relation was first obtained by a slow voltage command ramp from -140 to $-60 \mathrm{mV}$ at about $20 \mathrm{mV} / \mathrm{sec}$ (continuous line, control); ATP was then added and the ramp was repeated (continuous line, ATP). The $I / V$ relation was then obtained by measuring the current at the end of step hyperpolarization from the holding potential of $-60 \mathrm{mV}$, first in the absence of ATP (open circles), second in the presence of ATP (solid squares), and third after washing out ATP (solid circles). D, Voltage dependencc of current evoked by ATP in control solution (no TTX), determined by subtraction from experiments such as shown in C. Error bars indicate SEM; 10 or 11 cells at each point. out applications up to $2 \mathrm{~min}$. Higher concentrations of ATP evoked an inward current that declined in amplitude over several seconds and reached a sustained value that was usually only $10-30 \%$ of the peak amplitude (Fig. 1). The current declined during 15-20 sec when the ATP application was discontinued. The peak amplitude of the inward current depended on the concentration of ATP in the range of 1-300 $\mu \mathrm{M}$ (see below). In most cells, a small outward current flowed for 2-5 min after washing out ATP. Responses to ATP could be evoked repeatedly at intervals of 5 min during whole-cell recordings lasting up to $2 \mathrm{hr}$. Neurons in the immcdiatcly adjacent nuclcus parabrachialis $(n=10)$ and mesencephalic nucleus of the trigeminal nerve $(n=12)$ were not affected by ATP $(100-300 \mu \mathrm{M})$.

Membrane conductance was slightly decreased during the initial transient part of the response and clearly increased during the later sustained component. The decrease measured $15 \mathrm{sec}$ after beginning the ATP $(100 \mu \mathrm{M})$ application was $1.17 \pm 0.11$ $\mathrm{nS}(n=22)$, and the increase measured at $60 \mathrm{sec}$ (during the steady state) was $1.25 \pm 0.20 \mathrm{nS}(n=19)$. In cells that did not show the initial transient response to ATP, there was only an increase in membrane conductance.

Calcium-free/high-magnesium (10 mm) solution did not block the response to ATP. In fact, the peak current was often greater than that seen in control solution. In control solution, the mean peak current induced by ATP was $78 \pm 8.1 \mathrm{pA}(n=15)$ (Fig. 2). In the same neurons superfused with calcium-free/high-magnesium solution, it became $89 \pm 11 \mathrm{pA}$. The response to ATP desensitized more rapidly and completely in calcium-free, highmagnesium solution. Reducing the extracellular chloride concentration to $14 \mathrm{~mm}$ also had no effect on the amplitude and time course of ATP response (control, $113 \pm 26 \mathrm{pA}$; low-chloride solution, $122 \pm 29 \mathrm{pA} ; n=5$, at $-60 \mathrm{mV}$ ).

Most locus coeruleus neurons showed oscillations in mem- brane current of $25-100 \mathrm{pA}$ amplitude at $0.5-4 \mathrm{~Hz}$ (e.g., Fig. $1 B$ ); these were abolished in calcium-free solution, as in neonatal cells (Christie et al., 1989). Although not studied in detail, ATP reduced the amplitude and increased the frequency of these oscillations.

\section{Voltage dependence of ATP current}

The response to ATP became larger with hyperpolarization and smaller with depolarization, relative to the usual holding potential of $-60 \mathrm{mV}$ (Fig. $1 B$ ). Depolarization beyond $-40 \mathrm{mV}$ was usually not possible bccausc of spikelike oscillations in membrane current, presumably resulting from calcium action potentials in unclamped regions of the cell; these were blocked with calcium-free/high-magnesium solution, permitting the $I / V$ relation to be determined over a wider voltage range. The ATPinduced current decreased with depolarization and reversed to outward at $-2.2 \pm 5.5 \mathrm{mV}(n=10)$ (Fig. $2 B, C)$. However, in calcium-free solution, the ATP-induced current increased little or not at all with hyperpolarization (Fig. 2C).

\section{Role of sodium ions}

The reversal of the current at about $0 \mathrm{mV}$ indicates that a sodium or cation conductance is increased by ATP, as seen in a variety of other cells (see Silinsky, 1989). This is consistent with the observation that the sustained component of the response to ATP was associated with an increase in membrane conductance. Further cvidence for the involvement of sodium was sought by reducing the extracellular sodium concentration.

Low-sodium solutions markedly reduced the amplitude of the ATP current (Fig. 3A). With $50 \%$ and $87 \%$ substitution of sodium by Tris $\mathrm{HCl}$, the current induced by ATP was, respectively, $51 \pm 4.4 \mathrm{pA}(n=3)$ and $14 \pm 3.0 \mathrm{pA}(n=37)$, reductions of $37 \%$ and $88 \%$ when compared to the effect of ATP in normal 
Figure 2. Effects of ATP in calciumfree/high-magnesium (10 mM) solution, which allowed study of the voltage dependence over a wider potential range. $A$, Calcium-free/high-magnesium solution slightly increases the ATPinduced current at $-60 \mathrm{mV}$. $B$, currentvoltage plots before and after application of ATP in calcium-frec/high-magnesium solution. Current was plotted directly as a function of potential during a ramp command from -130 to +10 $\mathrm{mV}$ at $20 \mathrm{mV} / \mathrm{sec}$. $C$, Voltage dependence of ATP current in calcium-free solution, determined by subtraction from experiments such as shown in $B$; $8-10$ cells at each point.
A

Control

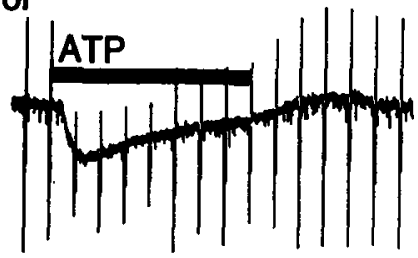

Calcium-free/high magnesium

Wash
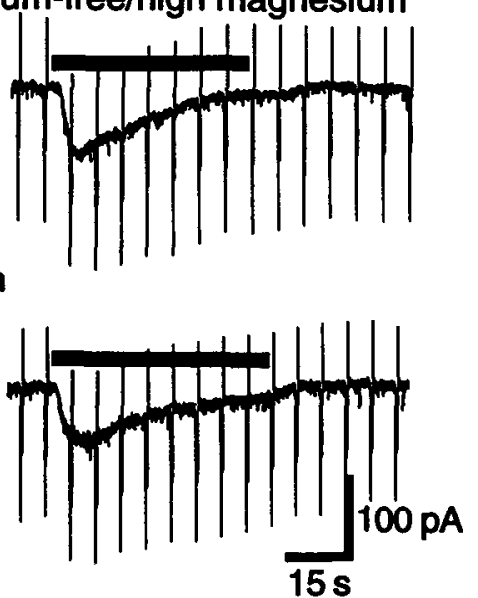

B
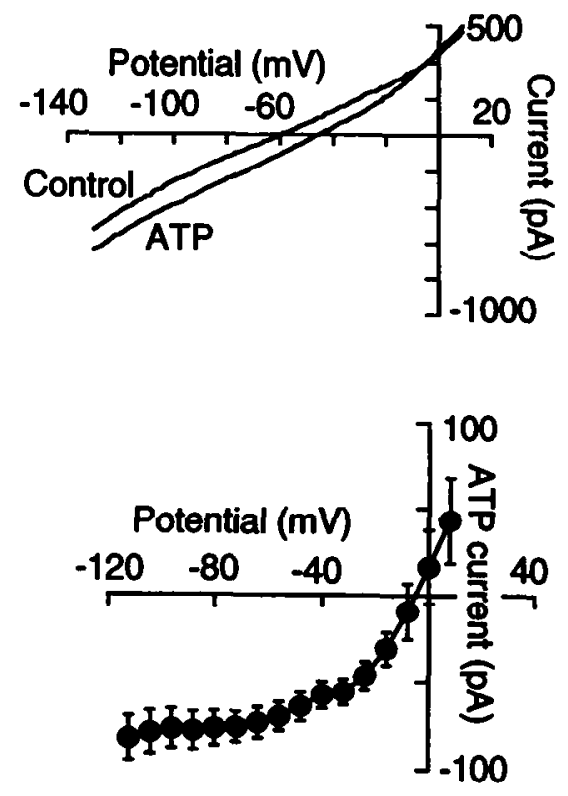

A

\section{Control}

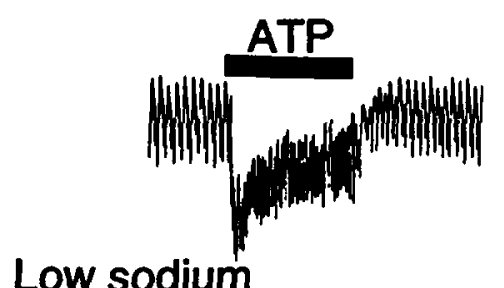

Low sodium

Wash
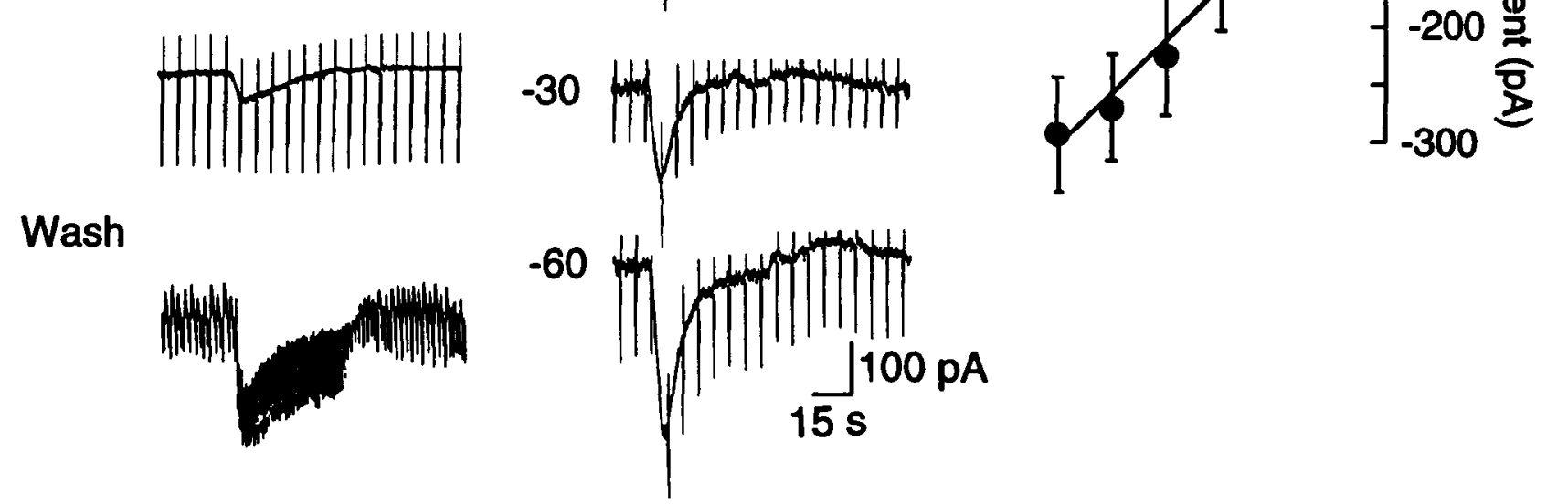

B

C

Figure 3. Sodium dependence of the ATP current. $A$, Superfusion with solution of low-sodium concentration (20 mM) reduced the amplitude of the ATP current; holding potential, $-60 \mathrm{mV} . B$ and $C$, Solution contained normal sodium, but neither internal nor external solution contained potassium ions (see text). $B$ shows voltage dependence of current evoked by ATP. Note slower time to peak and more rapid decline of the current compared with control solution (e.g., Fig. $3 A$ ). $C$, ATP current at different potentials in potassium-free solution. Line is fitted to mean values by squares minimization. 


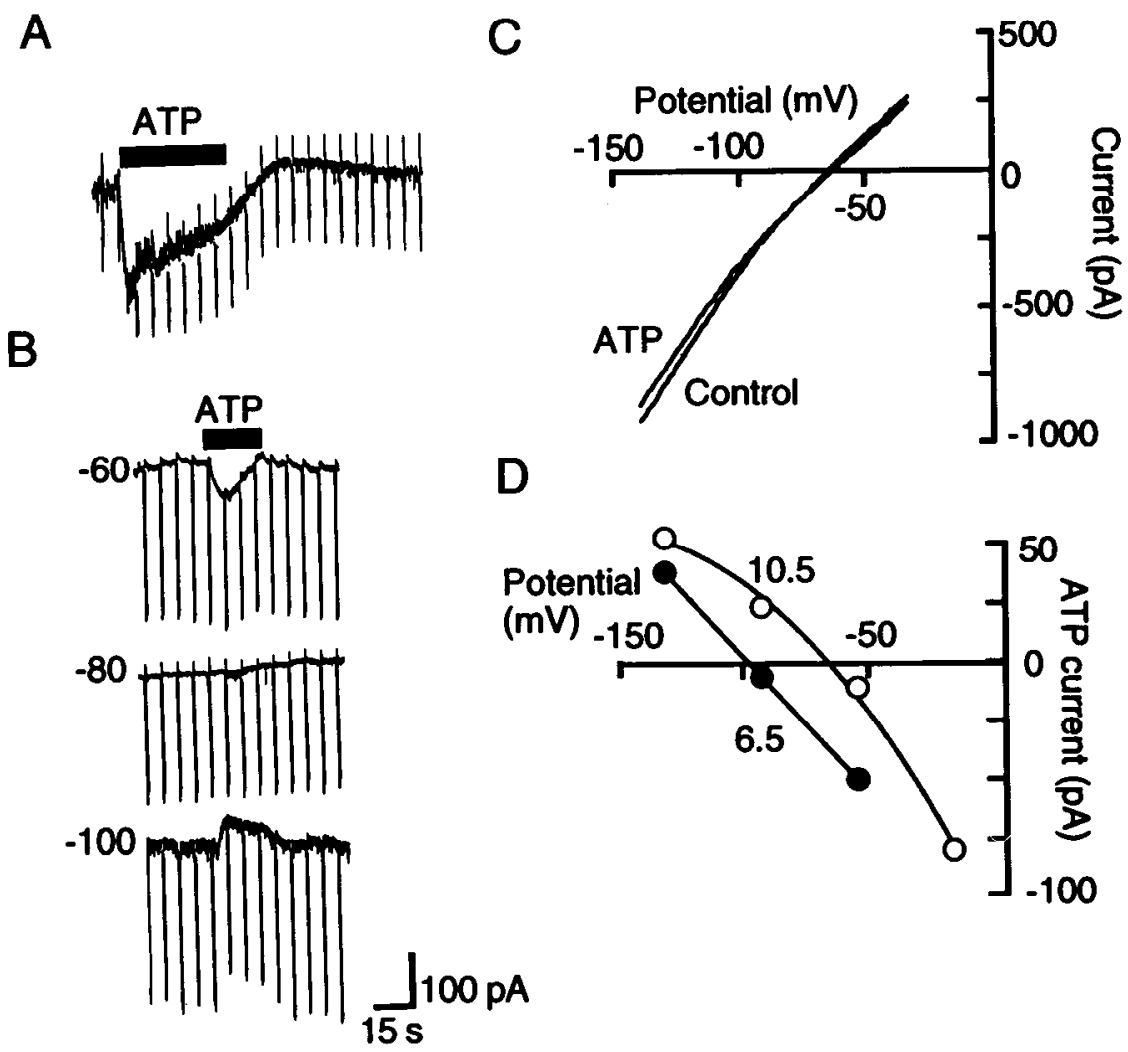

Figure 4. ATP decreases potassium conductance. $A$, Response to ATP $(300$ $\mu \mathrm{M})$ in normal solution at $-60 \mathrm{mV} . B$, Response of the same cell to ATP in low-sodium solution $(20 \mathrm{~mm})$ at three holding potentials (indicated beside each trace). Potassium concentration, 6.5 mM. Downward deflections are currents resulting from hyperpolarizing pulses $(10 \mathrm{mV}) . C$, Current-voltage relation in low-sodium solution $(20 \mathrm{~mm})$, before and after applying ATP. $D$, Voltage dependence of ATP current in lowsodium solution ( $20 \mathrm{~mm}$ ) (same cell as in $B$ ). Potassium concentrations were $6.5 \mathrm{~mm}$ and $10.5 \mathrm{~mm}$, as indicated.

sodium solution (113 $\pm 8.6 \mathrm{pA}, n=37)$. Similar results were observed whether sucrose, choline, or Tris was used to replace sodium. In low-sodium concentration ( $20 \mathrm{~mm})$, the current evoked by ATP rose more slowly to its peak, but declined completely during the application (Fig. $3 A, B$ ).

Evidence will be presented below that ATP reduces the potassium conductance of the locus coeruleus neurons. The sodium current component was therefore isolated by the removal of potassium ions (cesium gluconate in the pipette; extracellular solution contained no potassium but $3 \mathrm{~mm}$ cesium chloride, and no calcium but $10 \mathrm{~mm}$ magnesium). The membrane conductance of the cells was higher than normal in this solution $(14 \pm$ $1.5 \mathrm{nS}, n=13 ;-60 \mathrm{mV}$ ). ATP caused a response with an onset rate and initial peak similar to that seen in control condition, but the response declined rapidly and became completely desensitized during the application (Fig. 3B). The peak current was bigger than that seen in control conditions $(165 \pm 38.2 \mathrm{pA}$, $n=4)$. The ATP response was always associated with an increase of membrane conductance $(5.0 \pm 0.4 \mathrm{nS}, n=13)$, and the $I / V$ relation became essentially linear over the complete voltage range $(-120$ to $+20 \mathrm{mV})$ and reversed polarity at $10.7 \pm 1.1$ $\mathrm{mV}$ (Fig. 3C). Reduction of the sodium concentration to $20 \mathrm{~mm}$ in this condition markedly decreased the peak current of ATP response at $-60 \mathrm{mV}$ and shifted the reversal potential to the left (not shown).

\section{Role of potassium ions}

In the control conditions, the ATP-induced current did not increase as steeply with hyperpolarization as would be expected for a cation current reversing close to $0 \mathrm{mV}$ (Fig. $1 C, D$ ). Moreover, when the complete voltage range was examined in calcium-free/high-magnesium solution, the inward current showed a marked decrease at potentials negative to about $-60 \mathrm{mV}$ (Fig.
$2 C$ ). This could occur if the cation conductance undergoes voltage-dependent block by magnesium ions. However, the current elicited by ATP was not different in magnesium-free solution (control, $112 \pm 24 \mathrm{pA}$; in magnesium-free solution, $111 \pm 21$ $\mathrm{pA} ; n=6,-60 \mathrm{mV}$ ). We therefore considered another reason why the ATP-current might fail to increase with hyperpolarization, namely, a concomitant decrease in membrane potassium conductance.

In normal recording conditions, increasing the extracellular potassium concentration reduced the current evoked by ATP at $-60 \mathrm{mV}$. The ATP currents in $2.5,6.5$, and $10.5 \mathrm{~mm}$ potassium concentration were $119 \pm 24(n=6), 84 \pm 18(n=6)$, and $46 \pm 12(n=5) \mathrm{pA}$, respectively. These results suggest that a potassium conductance decrease contributes to the inward current at more negative potentials; this was studied further in conditions that would minimize the contribution of the inward sodium current.

At low $(20 \mathrm{~mm})$ sodium concentration, the response to ATP was associated with a decrease of membrane conductance and reversed polarity at $-81+3.3 \mathrm{mV}(n=5)$ in $6.5 \mathrm{~mm}$ potassium concentration and about $-65 \mathrm{mV}$ in $10.5 \mathrm{~mm}$ potassium concentration (Fig. 4). The current-voltage relation in ATP intersected the control $I / V$ at $-76.2 \pm 4.9 \mathrm{mV}(n=10,6.5 \mathrm{~mm}$ potassium concentration). ATP decreased the membrane conductance by $0.83 \pm 0.14 \mathrm{nS}(n=8)$ at $-50 \mathrm{mV}$ and by $0.88 \pm$ $0.22 \mathrm{nS}(n=8)$ at $-110 \mathrm{mV}$. This component of the response was not noticeably different when the recording electrode contained EGTA ( $11 \mathrm{~mm}, n=10$ ) or BAPTA ( $5 \mathrm{~mm}, n=3)$. The effect of low-sodium solution was reversible.

\section{Effect of ATP analogs and receptor antagonists}

Several analogs of ATP also caused inward currents (Fig. 5). These currents had the same features as described above, show- 

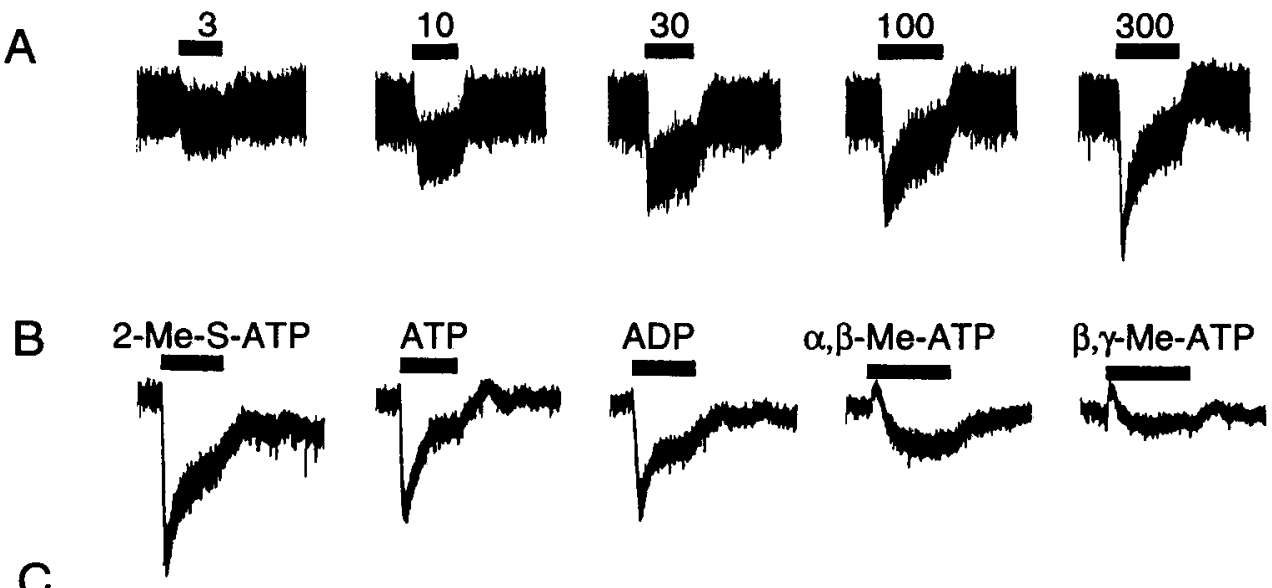

Figure 5. A, Concentration dependence of the action of ATP in one cell. Holding potential, $-60 \mathrm{mV}$. $B$, Typical responses to some ATP and analogs in a single cell. Holding potential, $-60 \mathrm{mV}$. All compounds were tested at $100 \mu \mathrm{M}$. $C$, ATP and ADP (each at $100 \mu \mathrm{M}$ ) have no effect on a neuron of the neighboring nucleus parabrachialis, but $30 \mu \mathrm{M}$ muscarine evoked an outward current.
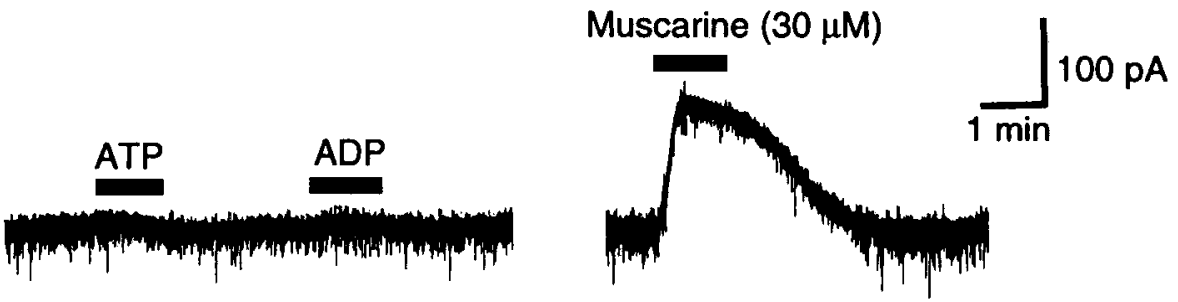

ing a marked decline during the application of higher concentrations. ATP and ADP were about equipotent, 2-Me-S-ATP was slightly more potent than these, whereas $\alpha, \beta-\mathrm{Me}$-ATP was less potent (Fig. 6). Maximal responses could usually not be obtained, and were roughly estimated by fitting the dose-response curves to a logistic function (Fig. 6); from such fits the concentrations giving "half-maximal" responses were 62,42 , 192 , and $19 \mu \mathrm{M}$ for ATP, ADP, $\alpha, \beta$-Me-ATP, and 2-Me-S-ATP, respectively. AMP, GTP, $\beta, \gamma \pm-M e-A T P$, and pyrophosphate (up to $300 \mu \mathrm{M}$ ) had no significant effect. Adenosine $(100 \mu \mathrm{M})$ caused small outward currents, consistent with previous reports that it hyperpolarizes locus coeruleus neurons (Shefner and Chiu, 1986).

The action of ATP was partially blocked by a high, desensitizing concentration of $\alpha, \beta$-Me-ATP. The $\alpha, \beta$-Me-ATP ( $3 \mathrm{~mm}$ ) evoked an inward current that peaked at $155 \pm 18 \mathrm{pA}(n=5)$ but that completely desensitized during a $3 \mathrm{~min}$ application. ATP $(30 \mu \mathrm{M})$ caused an inward current of $69 \pm 14 \mathrm{pA}(n=5)$ when applied during the presence of the $\alpha, \beta$-Me-ATP, compared with $128 \pm 11.5 \mathrm{pA}$ in control conditions.

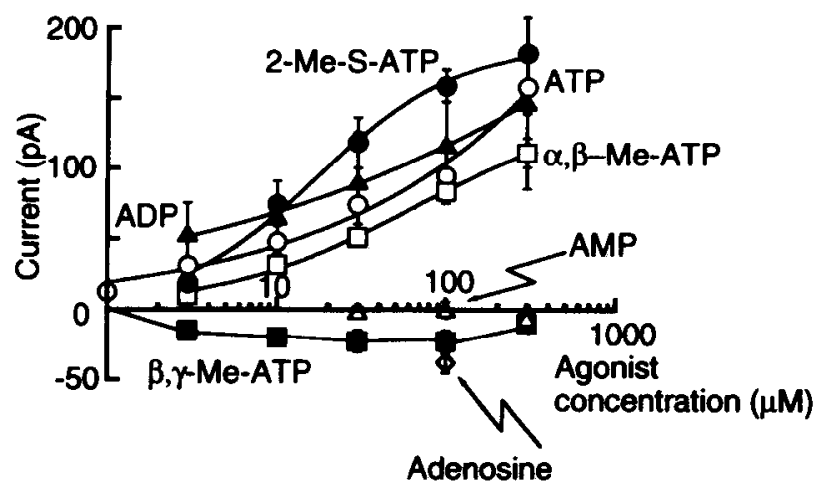

Figure 6. Currents induced by ATP and analogs. Cells were held at $-60 \mathrm{mV}$. Points are mean observations in $4-10$ cells, with SEM.
Currents induced by ATP were unaffected by a hexamethonium (500 $\mu \mathrm{M}, n=8)$, atropine $(1 \mu \mathrm{M}, n=7)$, and 8-cyclopentyltheophylline (30-300 $\mu \mathrm{M} ; n=6$ ), suggesting that nicotinic, muscarinic, and adenosine receptors were not involved. Idazoxan (1 $\mu \mathrm{M}, n=11)$ and 2-hydroxysaclofen $(300$ $\mu \mathrm{M}, n=6$ ) did not changc the responscs to ATP, indicating that noradrenaline or GABA released by excitation of surrounding cells did not play a role. Ouabain (3-20 $\mu \mathrm{M}, n=3$ ) had no effect on response of ATP, suggesting that the Na-K pump was not related to ATP-induced current. TTX also had no consistent effect on the inward current response to ATP.

\section{Discussion}

These experiments indicate that ATP acts at receptors of the $P_{2 Y}$ subtype to excite neurons of the rat locus coeruleus. This contrasts sharply with the effects of adenosine, which, acting through $\mathrm{A}_{1}$ receptors, hyperpolarizes the cells and inhibits firing (Shefner and Chiu, 1986; Regenold et al., 1990; see also Fig. 6). Our results also show that two distinct ionic mechanisms contribute to this excitatory action of ATP, when superfused onto the brain slice. The first is a decrease in the membrane potassium conductance; the sccond is an inward current through a nonspecific cation channel.

Evidence for the decrease in potassium conductance includes the decreased membrane conductance, the failure of the inward current to increase in amplitude with hyperpolarization, and most conclusively, the reversal of the response at the potassium equilibrium in low-sodium conditions. The second component of the response is referred to as a sodium conductance increase, but the reversal at $11 \mathrm{mV}$ implies that the channels opened are probably cation nonselective. This combination of ionic conductance changes is also induced in locus coeruleus neurons by muscarine (Shen and North, 1992a) and substance P (Shen and North, 1992b), and in autonomic neurons by muscarine (Tsuji and Kuba, 1988). The effect of muscarine of the locus coeruleus neurons was simulated in a "model neuron," in which an increase in a linear cation conductance was coupled with a de- 
crease in an inwardly rectifying potassium conductance; this indicated that at the resting potential of the cell the main component $(80-95 \%)$ of the inward current resulted from the cation conductance increase rather than the potassium conductance decrease (Shen and North, 1992a). The present experiments suggest that $\mathbf{P}_{2}$ receptors couple to the same effector mechanisms in the locus coeruleus as muscarine and substance $P$.

Cation conductance increase by ATP has been widely described for neurons of the PNS, but in most cases it results from activation of a ligand-gated channel termed the $P_{2 x}$ receptor, which undergoes rapid desensitization in the continued presence of the agonist (e.g., Jahr and Jessell, 1983; Krishtal et al., 1983; Bean, 1990; Allen and Burnstock, 1990; Fieber and Adams, 1991). This seems to be unlikely in the present experiments because the pharmacological properties of the receptor more closely resemble $P_{2 Y}$ than $P_{2 X}$. This would correspond more to the response of dorsal horn neurons to ATP described by Jahr and Jessell (1983) (a sustained depolarization) than to the response of the dorsal root ganglion cells in the same cultures (a transient desensitizing depolarization). However, further experiments with more selective agonists and antagonists (O'Connor et al., 1991), and with more rapid application methods would be required to settle this.

Potassium conductance decrease by ATP has also been reported in other cells. In $S$ neurons of the guinea pig myenteric plexus, ATP reduces a resting potassium conductance (Katayama and Morita, 1989), whereas in bullfrog ganglion cells ATP reduces a slow, outwardly rectifying conductance termed the $M$ conductance (Tokimasa and Akasu, 1990). Therefore, the present experiments show that mammalian central neurons can exhibit both these responses to ATP, and that both are found in the same cell. Activation of $\mathrm{P}_{2 \mathrm{Y}}$ receptors often stimulates phosphatidyl inositol metabolism (see Silinsky, 1989; O'Connor et al., 1991), and it will be important to test whether this underlies the changes in ionic conductance.

One can only speculate with regard to the physiological significance of this action of ATP. Catecholamine-containing cells often colocalize and secrete ATP. This raises the possibility that ATP is coreleased with noradrenaline by axon collaterals or dendrites (Aghajanian et al., 1977; Egan et al., 1983) of locus coeruleus neurons, or by adrenaline-containing fibers that enter the nucleus from the region of the nucleus prepositus hypoglossi (Aston-Jones et al., 1986). Application of suramin, or preferably more selective $\mathrm{P}_{2}$ receptor antagonists, to locus coeruleus neurons in vivo would be required to test these ideas.

\section{References}

Aghajanian GK, Vandermaelan CP (1982) $\alpha_{2}$-Adrenoceptor-mediated hyperpolarization of locus ceruleus neurons: intracellular studies in vivo. Science 215:1394-1396.

Allen TGJ, Burnstock G (1990) The actions of adenosine 5'-triphosphate on guinea-pig intracardiac neurones in culture. $\mathrm{Br} \mathbf{J}$ Pharmacol 100:269-276.

Aston-Jones G, Ennis M, Pieribone VA, Nickell WT, Shipley MT (1986)
The brain nucleus locus ceruleus: restricted control of a broad efferent network. Science 234:734-737.

Bean B (1990) ATP-activated channels in rat and bullfrog sensory neurons: concentration dependence and kinetics. J Ncurosci 10:1-10.

Burnstock G (1986) The changing face of autonomic neurotransmission. Acta Physiol Scand 126:67-91.

Christie MJ, Williams JT, North RA (1989) Electrical coupling synchronizes subthreshold activity in locus coeruleus neurons in vitro from neonatal rats. J Neurosci 9:3584-3589.

Egan TM, Henderson G, North RA, Williams JT (1983) Noradrenaline mediated synaptic inhibition in locus coeruleus neurones. $\mathbf{J}$ Physiol (Lond) 345:477-488.

Fieber LA, Adams DJ (1991) Adenosine triphosphate-evoked currents in cultured neurones dissociated from rat parasympathetic cardiac ganglia. J Physiol (Lond) 434:239-256.

Jackisch R, Fehr R, Hertting G (1985) Adenosine: an endogenous modulator of hippocampal noradrenaline release. Neuropharmacology 24:499-507.

Jahr CE, Jessell TM (1983) ATP excites a subpopulation of rat dorsal horn neurones. Nature 304:730-733.

Katayama Y, Morita K (1989) Adenosine 5'-triphosphate modulates membrane potassium conductance in guinea pig myenteric neurones. J Physiol (Lond) 408:373-390.

Kennedy $C$ (1990) $P_{1}$ and $P_{2}$ purinoceptors-an update. Arch Int Pharmacodyn Ther 303:30-50.

Krishtal OA, Marchenko SM, Pidoplichko VI (1983) Receptor for ATP in the membrane of mammalian sensory neurons. Neurosci Lett $35: 41-45$

Kuelgen IV, Schoffel E, Starke K (1989) Inhibition by nucleotides acting at presynaptic $\mathrm{P}_{2}$-receptors of sympathetic neuro-effector transmission in the mouse isolated vas deferens. Naunyn Schmiedebergs Arch Pharmacol 340:522-532.

Nicoll RA, Malenka RC, Kauer JA (1990) Functional comparison of neurotransmitter receptor subtypes in mammalian central nervous system. Physiol Rev 70:513-565.

O'Connor SE, Dainty IA, Leff P (1991) Further subclassification of ATP receptors based on agonist studies. Trends Pharmacol Sci 12: 137-143.

Regenold JT, Haas HL, Illes P (1990) Inhibitory adenosine $A_{1}$ receptors on rat locus coeruleus neurons. An intracellular study. Naunyn Schmiedebergs Arch Pharmacol 341:225-231.

Shefner SA, Chiu TH (1986) Adenosine inhibits locus coeruleus neurons: an intracellular study in a rat brain slice preparation. Brain Res 366:364-368.

Shen K-Z, North RA (1992a) Muscarine increases cation conductance and decreases potassium conductance in rat locus coeruleus neurones J Physiol (Lond) 455:471-485.

Shen K-Z, North RA (1992b) Substance P opens cation channels and closes potassium channels in rat locus coeruleus neurons. Neuroscience 50:345-353.

Shinozuka K, Bjur RA, Westfall DP (1988) Characterization of prejunctional purinoceptors on adrenergic nerves of the rat caudal artery. Naunyn Schmiedebergs Arch Pharmacol 338:221-227.

Silinsky EM (1989) Adenosine derivatives and neuronal function. Semin Neurosci 1:155-165.

Tokimasa T, Akasu T (1990) ATP regulates muscarine-sensitive potassium currents in dissociated bull-frog primary afferent ncuroncs. J Physiol (Lond) 426:241-264.

Tsuji S, Kuba K (1988) Muscarinic regulation of two ionic currents in the bullfrog sympathetic neurone. Phuegers Arch 41 1:361-370.

Williams JT, North RA, Shefner SA, Nishi S, Egan TM (1984) Membrane properties of rat locus coeruleus neurones. Neuroscience 13: $137-156$. 